doi: $10.15407 /$ ujpe62.11.0961

A.A. ABRAMOV, V.G. TKACHENKO

I.M. Frantsevich Institute for Problems of Materials Science, Nat. Acad. of Sci. of Ukraine (3, Krzhyzhanivs'kyi Str., Kyiv 03142, Ukraine; e-mail: icems@ipms.kiev.ua)

PACS 36.40.-c, 61.66.-f, 71.20.-b

\title{
FEATURES OF THE FORMATION OF CLUSTER COMPOUNDS IN METAL SOLID SOLUTIONS
}

\begin{abstract}
Physical origins of the chemical (energy) shifting of Auger electron lines in the spectra of Al$\mathrm{Li}, \mathrm{Ba}$ (by $1.4 \mathrm{eV}$ ) and $\mathrm{Mg}-\mathrm{Ba}$ (by $2 \mathrm{eV}$ ) systems containing cluster-forming alloying elements such as barium have been discussed. The observed peaks are associated with the formation of $A l_{18} B a_{9}$ and $\mathrm{Mg}_{16} \mathrm{Ba}_{2}$ cluster compounds characterized by their own electron configurations.

Keywords: cluster compounds, Auger electron spectrum, chemical (energy) shifts.
\end{abstract}

\section{Introduction}

The revelation of existing relationships between the physical properties of metals and alloys, on the one hand, and their electron structure, on the other hand, still remains the main task of solid state physics till now. With diminishing the spatial scales, the forms of a structural organization of matter, the fundamental laws of its motion, and its functional properties are changed. For instance, in polyatomic systems and multicomponent alloys (on the atomic level and at interatomic distances), the contribution of collective interactions between atoms, corresponding cooperative phenomena, and bound states of atomic groups (clusters) becomes stronger [1]. In the recent years, the clusters and materials with clustered structure have become an object of intense researches, in which the theoretical (from the first principles) calculations, time-of-flight mass spectrometry, and laser sources were applied to produce single-sort anions and mixed clusters [2-4]. Their structural, electronic, magnetic, and optical properties substantially differ from those inherent in bulk phases and massive metals. The doping of metal clusters changes their chemical and physical properties.

(C) A.A. ABRAMOV, V.G. TKACHENKO, 2017
The high-resolution (about $0.01 \mathrm{~J} / \mathrm{g}$ ) differential scanning calorimetry provided the first evidence for the existence of exothermic reactions and the corresponding weak thermal effects in melts, which testify to a strong interaction between atoms in the precrystallization region near the melting point [5]. In such a way, a possibility to efficiently localize the unsaturated chemical bonds, which are responsible for the formation of structural and concentration inhomogeneities in liquid alloys in the form of chemical (cluster) compounds, can be realized on the mesoscopic level of collective (short-range) interactions. According to the theory of associated solid solutions, the variations in the thermodynamic properties of melts can arise owing to the formation of associates of different atoms, $\mathrm{A}_{m} \mathrm{~B}_{n}$, in them $[6,7]$.

The size mismatch between atoms in binary solid solutions always stimulates a short-range ordering, when a partial relaxation of the deformation energy is provided by the atoms, which are surrounded with smaller atoms and vice versa. The clustering phenomenon belongs to another possible form or type of local ordering, in which the closest neighboring particles are an excess of their own atoms [8]. The emergence of the clustering as a mode of the local ordering actually means that the deformation energy cannot be a single driving force of the local order- 
ing [9]. There are some calculations and quantitative formulations that associate the local order with the electron structure [10,11].

For open condensed systems with a long-range order partially broken by cluster compounds, a reliable correlation was found between the local electron density of states and an increase in the photoemission quantum yield in the UV spectral range [1]. Thereby, new opportunities become open for the development of a cluster technology to form nanosystems in mesoscopic pre- and postmelting regions on the basis of a common concept of short-range clustered structure for metal melts and their primary solid solutions with a record packing density of isolated cluster compounds (up to $10^{14} \mathrm{~m}^{-2}$ ) [12]. Furthermore, the chemically bound cluster compounds can provide a counteraction to the dislocation motion, which results in an increase in the critical shear stress and can ensure an additional hardening of the solid solutions of metal crystals (driven by the mechanism of formation of clusters).

In this connection, the main aim of this work is to substantiate a basic possibility to enhance the strength (energy) of chemical bonds in cluster compounds (with their own electron configuration) that are built into the crystal lattice of a primary solid solution. On this basis, it seems to be expedient to study the evolution of a cluster structure of separate short-range-order compounds in the systems of metal alloys such as hcp $\mathrm{Mg}-\mathrm{Ba}$, fcc $\mathrm{Al}-\mathrm{Li}$, and fcc $\mathrm{Al}-\mathrm{Li}-\mathrm{Ba}$.

\section{Research Objects and Methods}

The ingots of magnesium (99.6\% purity) and aluminum (99.99\% purity), as well as their alloys (with $\mathrm{Li}$ and $\mathrm{Ba}$ additives), were obtained, by following the standard melting technology (bottom pouring into a massive copper chill mold). The basic components were introduced, by using a ligature synthesized beforehand in an induction melting installation in the protective environment of highly pure argon.

Owing to a high sensitivity of positrons to crystalstructure defects and the localization of the latter in regions with an inhomogeneous distribution of the electron density, the method of electron-positron annihilation [13] was used in the present work to estimate the possibility of the pair-defect or so-called pre-cluster formation in hcp substitutional solid so- lutions. The field of local stresses induced by mobile atoms was a source of excess (not intrinsic, structural) vacancies. The capture of thermalized positrons in potential wells and their annihilation with conduction electrons took place on structural physical defects (vacancies, dislocation cores, etc.). The angular photon distribution spectrum was used to calculate the parameter $S$, which characterizes the probability of the positron annihilation at defects [14], and the defect size, i.e. the localization radius of the positron wave function, for the hcp $\mathrm{Mg}$ and hcp $\mathrm{Mg}-\mathrm{Ba}$ metal systems.

The probability and possible details of formation of cluster compounds built into the crystal structure of the primary $\alpha$-solid solutions fcc Al-Li, bcc $\mathrm{Ba}$, and hcp $\mathrm{Mg}-\mathrm{Ba}$ were estimated, by using the TEM method and electron microdiffraction patterns [15]. The methods of colloid chemistry make it possible to create aqueous solutions that are enriched with surfactants and transparent to the light radiation. The absorption spectra of those solutions allow one to detect the intensity redistribution between the 420-nm and 510-nm bands corresponding to the formation of 1-nm Au clusters (the nuclei of future Au particles) and 3-4-nm Au nanoparticles [16]. Thereby, the existence of a mechanism responsible for the transformation of nanoclusters into nanoparticles and vice versa is proved. For metal systems that are opaque to the radiation, the identification of nanoparticles of the cluster origin with the use of electron microdiffraction patterns demands the application of the short-term annealing for the size of cluster compounds in a solid solution to grow to values accessible for the study by TEM methods [5].

Experimental researches of the electron structure in hep $\mathrm{Mg}$, fcc $\mathrm{Al}$, and their alloys with barium and lithium were carried out on electron spectrometers ES-2402 and RSM-500, by using the X-ray emission (XES) and X-ray photoelectron (XPS) spectroscopies and by following the standard procedures [17]. The accuracy of the determination of a line maximum in the XPS spectra amounted to $\pm 0.05 \mathrm{eV}$, if an X-ray gun equipped with a magnesium anode with a $\mathrm{MgK}_{\alpha}$ radiation energy of $1253.6 \mathrm{eV}$ was used. The determination error for points in the XES spectra did not exceed $\pm 1 \mathrm{eV}$.

The Auger electron spectra of alloys were registered, by following the standard procedure and using an Auger microprobe JUMP-105 (JEOLC) with a 
Positron annihilation parameters for nominally pure $\mathrm{Mg}$ and its alloy with $\mathrm{Ba}$

\begin{tabular}{|c|c|c|c|c|c|}
\hline Composition & $\begin{array}{c}\text { Area of } \\
\text { parabola, Sp, \% }\end{array}$ & $\begin{array}{c}\text { Area of } \\
\text { Gaussian, Sg, \% }\end{array}$ & $\begin{array}{c}\sigma_{F}, \\
\mathrm{~m} \text { rad }\end{array}$ & $\begin{array}{c}R_{m}, \\
\mathrm{~nm}\end{array}$ & $\begin{array}{c}\text { Defect size (localization radius } \\
\text { of the positron wave function), nm }\end{array}$ \\
\hline $\mathrm{Mg}$ & 75.4 & 24.6 & 5.32 & 0.060 & 0.156 \\
$\mathrm{Mg}-2.1 \mathrm{Ba}$ & 78.1 & 21.9 & 5.09 & 0.063 & 0.079 \\
\hline
\end{tabular}

probe $1-10 \mu \mathrm{m}$ in diameter. It is activated to a depth of $1-2 \mathrm{~nm}$ in the analyzed region. The energy distribution curves of emitted Auger electrons were studied in the $d N / d E$ mode, where $E$ is the electron binding energy, on a spectrometer with a maximum electron energy of $10 \mathrm{keV}$ and a limiting analyzer energy resolution of $0.3 \%$. After the ionic treatment with 1 $\mathrm{keV} \mathrm{Ar}^{+}$ions, the low-energy peaks of Auger electron spectra (LVV transitions) were registered for moulded states of hpc Mg, fcc Al, and their low-doped alloys with barium and lithium. The Auger effect is a radiationless transition (relaxation) with the electron emission, which is the autoionization of excited atoms owing to the internal electron conversion. This effect allows the method of Auger electron spectroscopy to be used for elucidating the nature of chemical bonds [17].

\section{Experimental Results and Their Discussion}

\subsection{Pre-cluster formation of pair defects}

The field of stresses created by mobile hydrogen atoms is a source of excess (not intrinsic, structural) vacancies. The concentration of those point-like defects in the Al-H system is by two to three orders of magnitude higher than the concentration of thermally equilibrium vacancies in fcc $\mathrm{Al}$ [1]. In this case, additional hydrogen vacancies $V_{i}$ facilitate the formation and identification of pair defects "dissolved atom- $\mathrm{V}_{i}$ vacancy". Therefore, the pre-cluster formations were first found in fcc solid solutions of the fcc $\mathrm{Al}-\mathrm{H}$ system.

According to the data of work [14], the positrons annihilate with the probability $S$ in regions with low electron concentrations typical of structural defects and redundant vacancies and dislocations, which become traps to capture and to localize positrons. The parameter $S$ for deformed fcc Al exceeds the corresponding value for the recrystallized metal by $4 \%$. This fact means that practically all positrons annihilate at structural defects in the course of structural relaxation. The saturation of the interstitial solid so- lution Al-H diminishes firstly the parameter $S$ (because the concentration of hydrogen atoms, i.e. electron donors, grows) and then increases it by $1.6 \%$ owing to the generation of excess (structural hydrogen) vacancies and the formation of "H atom- $\mathrm{V}_{i}$ vacancy" pair defect.

Similar effects were also observed in limited hcp solid solutions of the $\mathrm{Mg}-\mathrm{Ba}$ system. The appearance of pre-cluster pair-defect formations in hcp substitutional solid solutions is also confirmed by the results of positron annihilation researches (see Table).

In the framework of the adopted procedure of approximation of the spectrum as a superposition of a parabola and a Gaussian curve, the almost double reduction of the positron wave-function localization radius in alloys of the $\mathrm{Mg}-\mathrm{Ba}$ system (in comparison with $\mathrm{Mg}$ ) testifies that $\mathrm{Ba}$ atoms are really localized near vacancies and diminish the positron localization radius.

With the help of the electric resistance and smallenergy X-ray scattering methods, it was shown that the pre-precipitates with an activation energy of $0.69 \pm 0.04 \mathrm{eV}$ emerge in the substitutional alloys of the fcc $\mathrm{Al}-\mathrm{Zn}-\mathrm{Mg}-\mathrm{Cu}$ system at the earliest stages of aging in the form of dissolved pair defects. The corresponding diffusion process was identified with the migration of a Mg-V complex (a pair defect) [18].

Because of a size mismatch, the formation of a bond between a big dissolved atom creating a local stress field and a vacancy in a solid solution becomes energetically beneficial for the relaxation of an elastic deformation caused by the atom accompanied by a distortion of the frequencies of phonon oscillations (the first derivative of atomic forces, $d F / d x$, or $\left.d^{2} E / d x^{2}\right)$. In this case, the formation of a pair defect (with the negative released energy) reduces the formation energy of an extra vacancy by a value equal to the binding energy of this pre-cluster formation $[1,12]$. Nevertheless, in hexagonal metal crystals, e.g., in the hcp $\mathrm{Mg}-\mathrm{Ba}$ system, a monovacancy at the lattice site, as well as a separate dissolved barium atom 


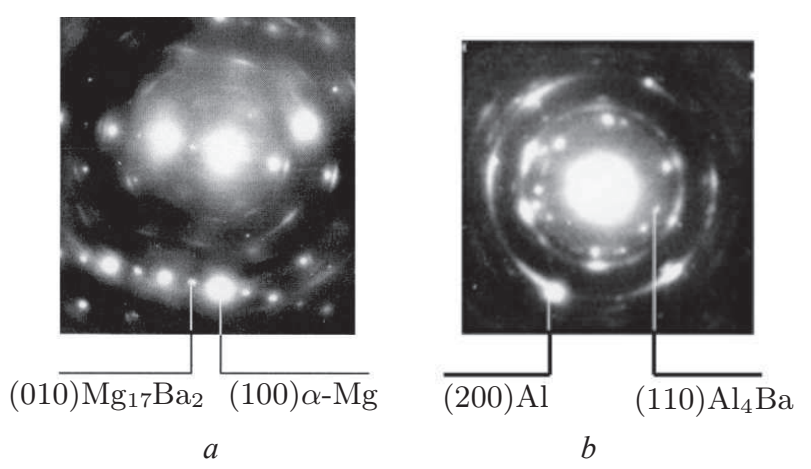

Fig. 1. Electron microdiffraction patterns with arc-shaped reflexes from the $\mathrm{Mg}_{16} \mathrm{Ba}_{2}$ cluster compound in the hcp $\mathrm{Mg}$ $2.1 \mathrm{Ba}$ system after the short-term annealing at $400{ }^{\circ} \mathrm{C}(a)$ and from the $\mathrm{Al}_{18} \mathrm{Ba}_{9}$ cluster compound in the fcc $\mathrm{Al}-1 \mathrm{Li}-3 \mathrm{Ba}$ system after a short-term annealing at $370{ }^{\circ} \mathrm{C}(b)$

with a $40 \%$ size mismatch, is not a relaxation center in the anisotropic hcp lattice, because, when being isolated, they preserve a low symmetry of the undistorted crystal.

The mechanical spectroscopy is characterized by a high structural sensitivity to thermally activated variations in the short-range order and the shortrange ordering of local structures. Therefore, in order to obtain more information about the existence of pair defects, the discrete temperature spectrum of the internal friction in the $\mathrm{Mg}-2.1 \mathrm{Ba}$ alloy was measured. At low oscillation frequencies (about $1 \mathrm{~Hz}$ ), a maximum in the resonance energy absorption was revealed at $413 \mathrm{~K}$, which is a result of the inelastic relaxation in the field of cyclic stresses created by primary (pre-cluster) pair-defect formations "Ba atom-extra vacancy" with an activation energy of $0.8 \mathrm{eV} /$ atom.

The results of those experimental researches agree with the literature data and the model ideas of Lomer, Embury, and Nicholson [19], who considered a basic possibility for the vacancy capture by dissolved atoms in dilute fcc solid solutions:

$C_{\mathrm{V}}=A \exp \left(-E_{\mathrm{f}} / k T\right)\left[1-12 c+12 c \exp \left(\frac{E_{\mathrm{B}}}{k T}\right)\right]$,

where $C_{\mathrm{V}}$ is the concentration of vacancies $\left(C_{\mathrm{V}} \approx\right.$ $\approx 10^{-4} \mathrm{~cm}^{-3}$ at the melting temperature, and $10^{-13} \mathrm{~cm}^{-3}$ at room one), $E_{\mathrm{f}}$ the vacancy formation energy, $E_{\mathrm{B}}$ the cluster binding energy, and $c$ the concentration of dissolved atoms.

Vacancies affect the kinetics of phase transitions, e.g., the fcc-bcc transition in alloys of the Fe-Ni system [20]. Vacancy pair defects and other complexes of point defects create the asymmetric deformations around themselves (to be exact, these are atomic displacements in a vicinity of this defect). In such a manner, they become the centers of local loss of the crystal lattice stability and provide, in particular, the diffusionless character of structural (martensitic) transformations [21].

\subsection{Short-range clustered compounds}

Electron microdiffraction patters provide a useful information about the defect (cluster) structure of solid solutions. In particular, the observed strip-like reflexes (see Fig. 1) are interpreted as the stretching of sites in the reciprocal lattice. They are associated with ordered domains, which are coherent with the matrix and arranged in a certain lattice direction [15]. According to TEM data, some clusters create the black-white contrast typical of small centers of a crystal lattice deformation in the solid solution [22]. According to the electron microdiffraction patters (Fig. 1), the crystalline structure of a $\mathrm{Mg}_{m} \mathrm{Ba}_{n}$ cluster is, in essence, a weak distortion of the hcp lattice of the $\alpha$-Mg matrix with interfaces, which are sources of high local stresses.

It is worth to emphasize that the prolate (arc-shaped) and smeared reflexes of the matrix are formed in the reflexes, e.g., of the $\mathrm{Al}_{4} \mathrm{Ba}$ phase (Fig. 1,b). This fact means that the main evidence that the clustered compound $\mathrm{A}_{m} \mathrm{~B}_{n}$ does exist is the affinity of the crystal lattice parameters for the chemical (stoichiometric) compound (phase) and the quasicrystalline lattice of $\mathrm{A}_{m} \mathrm{~B}_{n}$ clusters built into the crystal structure of the primary $\alpha$-solid solution, i.e. (cl) $\mathrm{Al}_{18} \mathrm{Ba}_{9} \Rightarrow$ $\Rightarrow(\mathrm{ph}) \mathrm{Al}_{4} \mathrm{Ba}$ and $(\mathrm{cl}) \mathrm{Mg}_{16} \mathrm{Ba}_{2} \Rightarrow(\mathrm{ph}) \mathrm{Mg}_{17} \mathrm{Ba}_{2}$.

The cluster compound $\mathrm{A}_{m} \mathrm{~B}_{n}$ is an integral component of the quasicrystalline solid-solution structure. In those clusters, the crystal lattice is distorted to a larger extent, which is confirmed by the appearance of additional diffusion reflexes with a weak intensity (Fig. 1) or a moire contrast associated with the presence of intermediate distances between the planes [15]. On this basis, a cluster built into the lattice of a metal or semiconductor matrix is assumed to be determined by the atomic packing density, rather than by the atomic structure [23]. In other words, instead of an interphase surface between the cluster and the matrix, there emerges a smooth transition between them as a result of the violation of the periodicity in an irregular structure and the chemical bond length. 
Therefore, there is a reason to suppose that the cluster-forming alloying element $\mathrm{Ba}$ changes the nature of a local short-range bond in the fcc Al-Li system due to the formation of isolated clustered compounds $\mathrm{Al}_{m} \mathrm{Ba}_{n}$, which preserve their high density and individual properties in the matrix crystal lattice with a partially broken long-range order. The clustering in the structure of substitutional solid solutions shifts the optical absorption maximum in the UV spectral range owing to the growth in the electron density of states near the Fermi energy level. This conclusion is confirmed by researches of the spectral sensitivity of the photoemission quantum yield from metal alloys containing a high concentration of clustered compounds $\mathrm{Mg}_{m} \mathrm{Ba}_{n}$ and, in such a way, providing a record packing density (up to $10^{14}-10^{16} \mathrm{~m}^{-2}$ ) for the sources of optical excitation (nanoemitters) [24]. If the concentration of such nanoclusters reaches a value of $5 \times 10^{14} \mathrm{~m}^{-2}$, the low photoemission quantum yield typical of nominally pure metals $(\mathrm{Mg}$, $\mathrm{Al}, \mathrm{Cu}$ ) becomes larger by two to three orders of magnitude.

The results of our researches are confirmed by the data of Auger electron spectroscopy, which is characterized by a high element sensitivity to the chemical state of the substance [17]. In the low-energy regions of Auger spectra registered for the $\mathrm{Mg}-1 \mathrm{Ba}$ and $\mathrm{Al}-$ 2Li alloys, chemical (energy) shifts were found, which are a result of a redistribution in the density of states (in the valence band, this is the charge redistribution) and a change in the binding energy of electrons (Figs. 2 and 3). The variation in the amplitude of Auger electron peaks reflects the variation in the intensity of Auger electron transitions. The shape of the Auger spectral lines of chemical compounds is simulated by the local density of states (DOS) of valence electrons, i.e. the summed Auger electron emissions from the levels in the valence band [25]. The $\mathrm{L}_{23} \mathrm{VV}$ Auger electron transition in the alloy $\mathrm{Mg}-1 \mathrm{Ba}$ with the cluster-forming structure of a substitutional solid solution becomes shifted (by the binding energy) by $2.0 \mathrm{eV}$ toward the region with the maximum density of states (Fig. 2), and by only $0.4 \mathrm{eV}$ in the alloy Al-2Li with the donor-acceptor (coordination) bond (Fig. 3).

This discrepancy means that the level of optical (emission) properties depends on the chemical bond nature. A more effective charge redistribution of valence electrons in $\mathrm{Mg}-\mathrm{Ba}$ alloys with an ex-
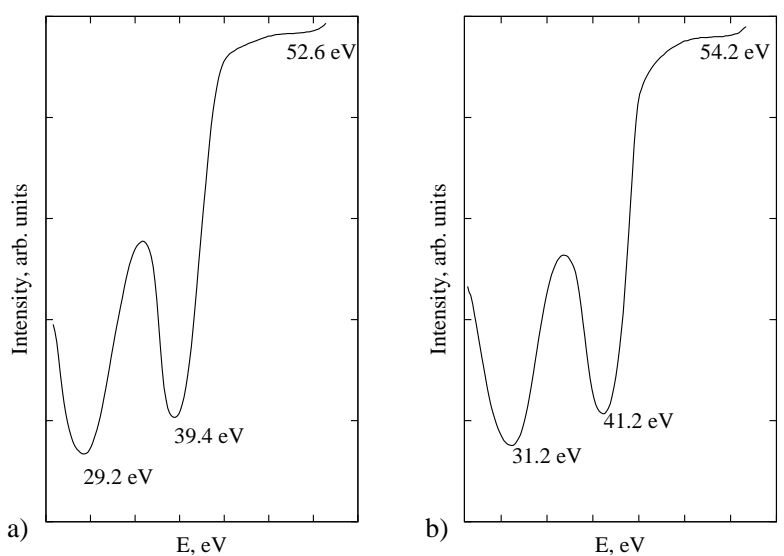

Fig. 2. Experimental low-energy spectrum of LVV Auger electron transitions for $\mathrm{Mg}(a)$ and $\mathrm{Mg}-1 \mathrm{Ba}$ alloy with a chemical (energy) shift of about $2.0 \mathrm{eV}(b)$
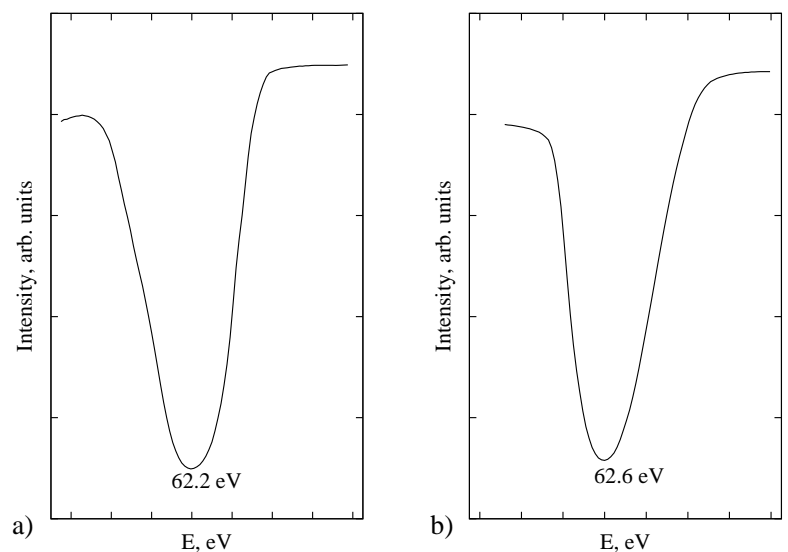

Fig. 3. Experimental low-energy spectrum of LVV Auger electron transitions for $\mathrm{Al}(a)$ and $\mathrm{Al}-2 \mathrm{Li}$ alloy with a chemical (energy) shift of about $0.4 \mathrm{eV}(b)$

tremely low true (lattice) solubility of their components is associated with the short-range ordering of atomic Ba groups following the clustering mechanism. Theoretical calculations carried out making use of FLAPW approximations for the cluster potential predict a basic possibility for the formation of an own electron structure in clusters with a stronger chemical bond owing to a displacement of the center of gravity of $d$-states at the Fermi surface and the overlapping of electron wave functions for the $s$ and $p$ states of the matrix, on the one hand, and the $d$ states of $\mathrm{Ba}$, on the other hand $[1,26,27]$. Three stable states of atomic groups were revealed with magic atomic numbers of 2, 8, and 18; which points to the electron 

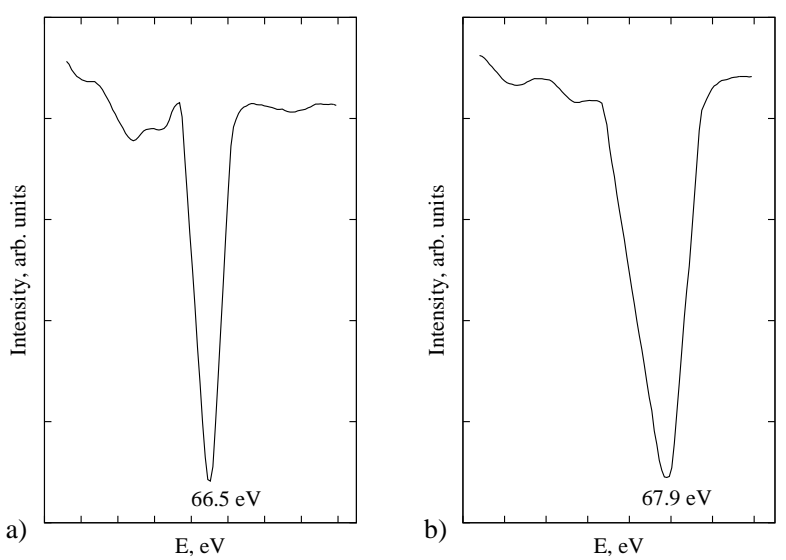

Fig. 4. 1.4-eV chemical shift (for the binding energy of valence electrons) of the low-energy Auger peak in the fcc Al-2Ba system (the ion cluster deposition method): LVV Auger transition for $\mathrm{Al}(a)$; LVV Auger transition for $\mathrm{Al}-2 \mathrm{Ba}$ alloy $(b)$

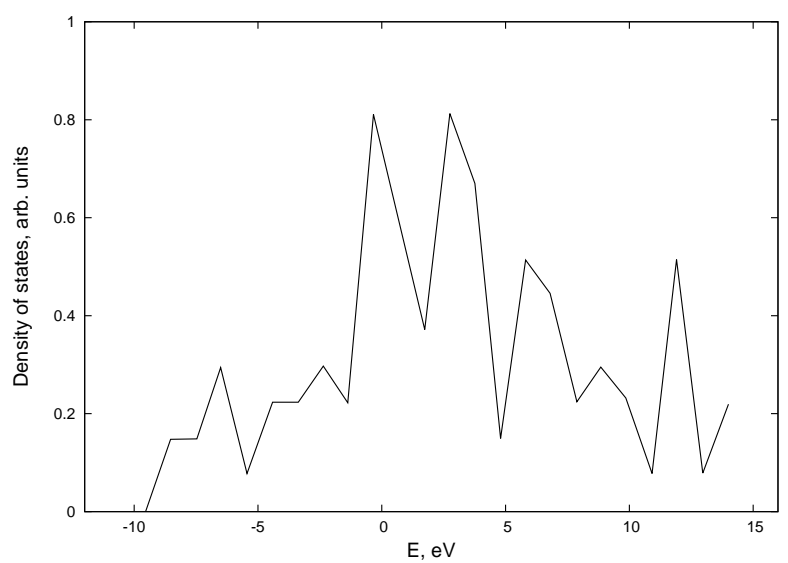

Fig. 5. Total electron density of states in an $\mathrm{Al}_{18} \mathrm{Ba} 9$ cluster with a quasicrystalline structure of the $\mathrm{Al}_{4} \mathrm{Ba}$ type in the fcc Al-Ba system

shell configuration of the $\mathrm{Mg}_{m} \mathrm{Ba}_{n}$ cluster with closed shells, i.e. $n=2,8,18,20,34,40,58$, and so forth for, respectively, $1 s, 1 p, 1 d, 2 s, 1 f, 2 p$ electrons, and so forth [1]. According to those data, primary nanoclusters of the vacancy origin, e.g., the $\mathrm{Mg}_{2}$-extra vacancy $(n=2)$, are self-assembled following the selfassembly mechanism (first, $\mathrm{Mg}_{6} \mathrm{Ba}_{2}$, i.e. $n=8$; afterward, $\mathrm{Mg}_{16} \mathrm{Ba}_{2}$, i.e. $n=18$ ) to form a cluster with its own electron configuration.

The results of our researches agree with the results of theoretical calculations, in which the cluster potential was completely approximated [26], and the results of quantum-mechanical calculations of the electron

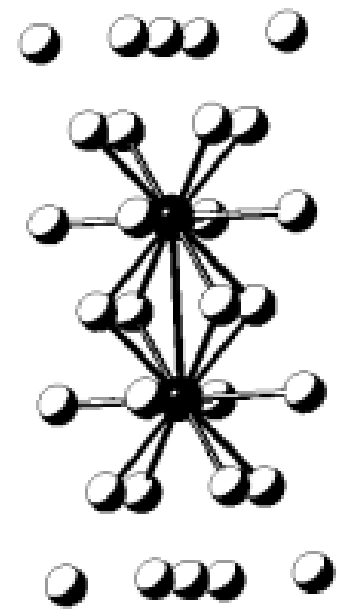

$a$

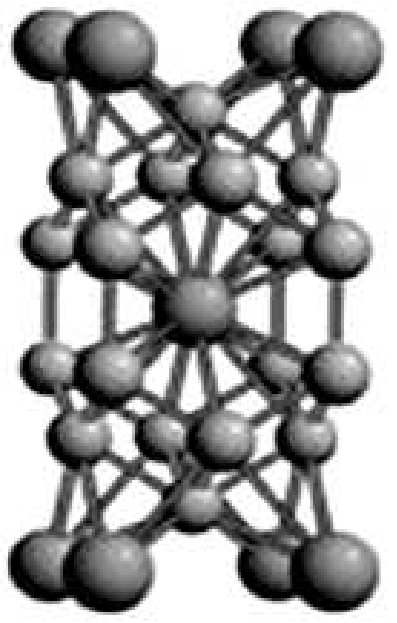

$b$
Fig. 6. Quasicrystalline structure of the $\mathrm{Al}_{m} \mathrm{Ba}_{n}$ compound: $\mathrm{Al}_{30} \mathrm{Ba}_{2}(a)$ and $\mathrm{Al}_{18} \mathrm{Ba}_{9}$ cluster (b)
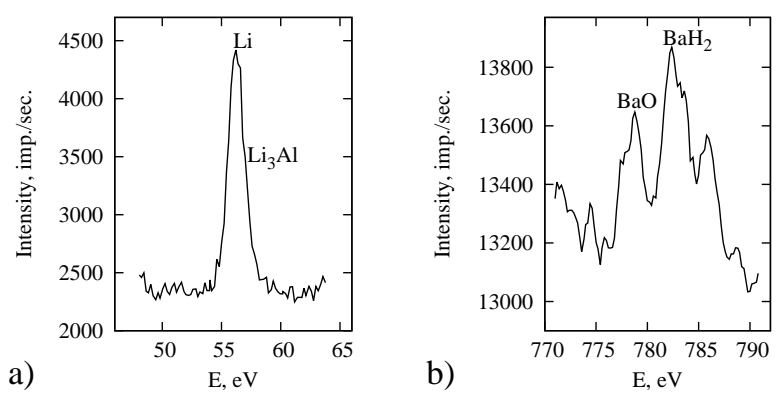

Fig. 7. Experimental XPS spectra of $\mathrm{Al}-2 \mathrm{Li}(a)$ and $\mathrm{Al}-2 \mathrm{Li}-$ $2 \mathrm{Ba}(b)$ alloys after their heating to $370^{\circ} \mathrm{C}$

configuration in $\mathrm{Mg}_{n} \mathrm{Ba}_{m}$ cluster compounds [1]. Furthermore, they are confirmed by the chemical shifts in the binding energy of valence electrons, which are much more effective in the cluster-forming Al-Ba system (by $1 \mathrm{eV}$, Fig. 4) than in the Al-Li system (by $0.4 \mathrm{eV}$, Fig. 3). Using the density functional method (in the framework of the electron density functional theory), it was proved that an $\mathrm{Al}_{18} \mathrm{Ba}_{9}$ nanocluster built into the crystal structure of the $\mathrm{Al}-\mathrm{Ba}$ primary solid solution and close to the structure of the stoichiometric phase $\mathrm{Al}_{4} \mathrm{Ba}$ can exist in principle [26].

Hence, a reasonable (most probable) interpretation of the observed Auger spectra is associated with the interaction of electrons in the valence band of hcp or fcc solid solutions. The results obtained agree with the Kucherenko-Aleshina-Nemoshkalenko model [28], in which the energy of the Auger elec- 
tron flux distribution is related to the local density of states $N_{i}(E)$ in the valence band, as well as the corresponding probabilities of radiationless Auger transitions. Nevertheless, the relaxation (redistribution) of valence electrons significantly distorts the electron spectrum profile (the energy distribution).

Nowadays, the quantum-mechanical calculations of electron configurations are considered to be a reliable tool for the identification and physical interpretation of the most probable short-range cluster compounds. Additional ab-initio calculations of the electron structure in the $\mathrm{Al}_{m} \mathrm{Ba}_{n}$ or $\mathrm{Al}_{m}(\mathrm{Li}, \mathrm{Ba})_{n}$ cluster compounds (Fig. 5) predict a hybridization of $\mathrm{Al}$ and $\mathrm{Ba}$ atomic orbitals by means of the overlapping of the electron $s$ and $p$ states of $\mathrm{Al}$, on the one hand, and the $d$ states of $\mathrm{Ba}$, on the other hand, and, as a consequence, an increase in the local density of states near the Fermi energy level owing to the activation of the short-range (at interatomic distances) mechanism governing the collective interaction of doping elements and the formation of $\mathrm{A}_{m} \mathrm{~B}_{n}\left(\mathrm{Al}_{m} \mathrm{Ba}_{n}\right)$ cluster compounds (Fig. 6).

The additional analysis of electron configurations in the $\mathrm{Al}-2 \mathrm{Li}$ and $\mathrm{Al}-2 \mathrm{Li}-2 \mathrm{Ba}$ alloys by XPS methods showed that, after the heating to $370^{\circ} \mathrm{C}$ in the $\mathrm{Al}-\mathrm{Li}$ system, the alloying element $\mathrm{Li}$, owing to its donor-acceptor bond with $\mathrm{Al}$, forms the phase $\mathrm{Al}_{3} \mathrm{Li}$ (Fig. 7, a). At the same time, if the cluster-forming alloying element $\mathrm{Ba}$ is introduced, the spectrum of Ba3 $d_{5 / 2}$ internal states reveals additional lines in addition to $\mathrm{BaO}$ and $\mathrm{BaH}_{2}$ ones. The new lines are, most probably, of the cluster origin, being a result of the hybridization between the $s$ and $d$ states in the $\mathrm{Al}_{m} \mathrm{Ba}_{n}$ cluster. Therefore, the quantum yield of the photoemission in the $\mathrm{Al}-\mathrm{Li}-\mathrm{Ba}$ system increases by two to three orders of magnitude [26, 27].

According to the XES data [29], the electron configurations in the $\mathrm{Mg}-\mathrm{Al}-\mathrm{Ca}$ and $\mathrm{Mg}-\mathrm{Al}-\mathrm{Y}$ solid solutions demonstrate similar regularities. (i) In the $\mathrm{Mg}-$ $\mathrm{Al}$ system, $3 s$ electrons stimulate the hybridization of electron states in the $\mathrm{MgL}_{\alpha}$ valence band. In the $\mathrm{AlL}_{\alpha}$ valence band, a higher density distribution of $s$ electrons expands into the near-Fermi spectral region. (ii) In the $\mathrm{Mg}-\mathrm{Al}-\mathrm{Ca}(\mathrm{Y})$ system, the addition of dissolved $\mathrm{Ca}$ and $\mathrm{Y}$ atoms enhances the hybridization effect and increases the energy of chemical bonds in the crystalline structure of the $\mathrm{Mg}-\mathrm{Al}$ solid solution due to the overlapping between the $s$ states of $\mathrm{Mg}$ (the matrix) and the $d$ states of the alloying element.

\section{Conclusions}

1. Taking advantage of the electron-positron annihilation method, the first experimental evidence is obtained for the presence of excess vacancies (positron traps) in the substitutional solid metal solutions hcp $\mathrm{Mg}-2.1 \mathrm{Ba}$. The presence of interstitial atoms (in the fcc $\mathrm{Al}-\mathrm{Li}$ system) or alloying elements (in the hcp $\mathrm{Mg}-\mathrm{Ba}$ system) gives rise to a redistribution of the electron concentration in vicinities of the defects and a shift of the Fermi energy (the kinetic energy of electrons). The resulting generation of the excess negative charge is accompanied by the localization and strengthening of chemical bonds in the stress field of the Ba alloying element and the pre-cluster formation of a structural pair defect "Ba atom-extra vacancy $\mathrm{V}_{i}$ ". The physical properties of this defect are confirmed by the appearance of the inelastic relaxation effect, which becomes possible only due to the atomic reorientation of elastic dipoles giving rise to a distortion in the symmetry of the hcp lattice in the field of cyclic stresses.

2. The formation of a local short-range structure in the hcp and fcc solid solutions is accompanied by a change in chemical bonds, which is confirmed by the appearance of the so-called chemical shifts (the binding energy of valence electrons) in the low-energy sections of Auger electron spectra for the metal systems of cast alloys $\mathrm{Mg}-2.1 \mathrm{Ba}, \mathrm{Al}-2 \mathrm{Li}$, and $\mathrm{Al}-1 \mathrm{Li}-3 \mathrm{Ba}$.

3. A physical interpretation of observed effects is given. A substantial shift (up to $2 \mathrm{eV}$ in the $\mathrm{Mg}$ $\mathrm{Ba}$ system and $1.4 \mathrm{eV}$ in the $\mathrm{Al}-\mathrm{Li}-\mathrm{Ba}$ one) is explained by the formation of atomic groups of $\mathrm{A}_{m} \mathrm{~B}_{n}$ cluster compounds - more specifically, $\mathrm{Mg}_{16} \mathrm{Ba}_{2}$ and $\mathrm{Al}_{18} \mathrm{Ba}_{9}$ - with their own electron configurations created by the overlapping of the electron wave functions of the $s$ and $p$ states in a matrix and the $d$ states of the cluster-forming alloying element Ba.

4. The built-in crystalline structure of a cluster compound is an integral component of the crystalline structure of a solid solution. It induces a weak distortion in the crystal lattice of the matrix with the relaxed interface. In this case, the short-range ordering interferes with the recombination of atomic groups of cluster compounds $\mathrm{A}_{m} \mathrm{~B}_{n}$.

To summarize, it should be noted that the structure and properties of the examined hardening alloys significantly depend on the structural (clustered) state of their melts before the crystallization. The processes of alloy melting and crystallization become a 
natural technological medium for the self-assembling of genetically related atomic groups - in particular, short-range cluster compounds - in the mesoscopic regions of collective interactions between atoms and defects. The observed cooperative effects and anomalous phenomena, as well as the activation of the mechanism of short-range ordering with deviations from the classical Arrhenius relation for the diffusion mobility, Vegard's rule for homogeneous solid solutions, and the Cottrell-Bilby law for the solute atmosphere around dislocations, have a principal value for the understanding of the physical nature of the cluster formation in structures with a broken longrange order. They open new opportunities for the development of a technology aimed at the creation of nanosystems with controllable parameters.

1. V.G. Tkachenko, O.I. Kondrashev, I.M. Maksymchuk. Physical Foundations of Photoelectronics of Metal Crystals (Naukova Dumka, 2009) (in Ukrainian).

2. I.P. Suzdalev, P.I. Suzdalev. Discreteness of nanostructures and critical sizes of nanoclusters. Usp. Khim. 75, 715 (2006) (in Russian).

3. M.Yu. Siretskiy, M.G. Shelyapina, D. Fruchart, S. Miraglia, N.E. Skryabina. Influence of a transition metal atom on the geometry and electronic structure of $\mathrm{Mg}$ and $\mathrm{Mg}-\mathrm{H}$ clusters. J. Alloy. Compd. 480, 114 (2009).

4. J. Zhao, B. Liu, H. Zhai, R.Zhou, G. Ni, Z. Xu. Mass spectrometric and first principles study of $\mathrm{Al}_{n} \mathrm{C}^{-}$clusters. Solid State Commun. 122, 543 (2002).

5. V.G. Tkachenko, A.A. Shcheretskii, A.A. Abramov, A.N. Malka, A.S. Vovchok. Physico-mechanical properties of modificated magnesium alloys with cluster-forming melt structure. Elektron. Mikrosk. Prochn. Mater. No. 19, 52 (2013) (in Russian).

6. M. Sakata, N. Cowlam, H.A. Davies. Chemical short-range order in liquid and amorphous $\mathrm{Cu}_{66} \mathrm{Ti}_{34}$ alloys. J. Phys. F 11, L157 (1981).

7. W. van der Lugt, W. Geertsma. Liquid alloys with strong chemical interactions. J. Non-Cryst. Solids 61/62, 187 (1984).

8. P.S. Rudman. A theory of atom size difference induced short-range order. Acta Metallurg. 13, 387 (1965).

9. P.S. Rudman, B.L. Averbach. X-ray measurements of local atomic arrangements in aluminum-zinc and in aluminumsilver solid solutions. Acta Metallurg. 2, 576 (1954).

10. J. Friedel. Electronic structure of primary solid solutions in metals. Adv. Phys. 3, 446 (1954).

11. P.A. Flinn. Electronic theory of local order. Phys. Rev. 104, 350 (1956).

12. A.A. Abramov, V.G. Tkachenko, A.A. Shcheretskii, I.N. Maksimchuk, A.S. Vovchok. Supercooling features in liquid metal alloys with vatious chemical interaction of components. Elektron. Mikrosk. Prochn. Mater. No. 20, 52 (2014) (in Russian).

13. M.M. Nishchenko. Electronic Structure of Transition Metals, Their Alloys, and Intermetallic Compounds (Naukova Dumka, 1979) (in Russian).

14. V.G. Tkachenko, B.G. Strongin, I.N. Maksimchuk, V.V. Friesel, V.P. Grechko, S.P. Likhtarovich. Peculiarities of solid solution decay of hydride-forming and non-hydrideforming systems with close-packed crystal structure. Int. J. Hydrogen Energ. 21, 1091 (1996).

15. K.W. Andrews, D.J. Dyson, S.R. Keown. Interpretation of Electron Diffraction Patterns (Hilger and Watts, 1971).

16. M.G. Spirin, S.B. Brichkin, V.F. Razumov. Specifics of the preparation of anisotropically shaped gold nanoparticles in triton x-100 reverse micelles. Khim. Vys. Energ. 44, 54 (2010) (in Russian).

17. K. Siegbahn, C. Nordling, A. Fahlman, R. Nordberg, K. Hamrin. J. Hedman. G. Johansson, T. Bergmark, S.E. Karlsson, I. Lindgren, B. Lindberg. ESCA: Atomic, Molecular and Solid State Structure Studied by Means of Electron Spectroscopy (Almqvist and Wiksells, 1967).

18. R. Ferragut, A. Somoza, I. Torriani. Pre-precipitation study in the $7012 \mathrm{Al}-\mathrm{Zn}-\mathrm{Mg}-\mathrm{Cu}$ alloy by electrical resistivity. Mater. Sci. Eng. A 334, 1 (2002).

19. J.D. Embury, R.B. Nicholson. The nucleation of precipitates: The system Al-Zn-Mg. Acta Metallurg. 13, 403 (1965).

20. P. Entel, K. Radau, L. Meyer, H.C. Herper, M. Schröter, E. Hoffmann. Large-scale molecular-dynamics simulations of martensitic nucleation and shape-memory effects in transition metal alloys. Phase Trans. 65, 79 (1998).

21. Yu.N. Gornostyrev, M.I. Katznelson, A.V. Kuznetsov, A.V. Trefilov. Simulation of martensitic transformations in a crystal with dislocations of various types in bcc-Zr. Fiz. Met. Metalloved. 91, No. 3, 32 (2001).

22. B.L. Eyre, J.H. Evans. An electron microscope study of the low temperature ageing behaviour of quenched molybdenum-nitrogen alloys. Acta Metallurg. 20, 267 (1972).

23. Yu.G. Poltavtsev. Structure of Semiconductor Melts (Metallurgiya, 1984) (in Russian).

24. V.G. Tkachenko, A.I. Kondrashev, I.N. Maksimchuk. Advanced metal alloy systems for massive high-current photocathodes. Appl. Phys. B 98, 839 (2010).

25. R. Weissmann, K. Müller. Auger electron spectroscopy a local probe for solid surfaces. Surf. Sci. Rep. 1, 251 (1981).

26. V.G. Tkachenko, L.R. Shaginyan, A.I. Kondrashev, V.L. Bekenev, A.A. Lisenko, V.V. Kartuzov. Nanostructured emission-active aluminum alloys for high-current photocathodes with laser excitation. Nanostrukt. Materialoved. No. 4, 69 (2010) (in Russian).

27. V.G. Tkachenko, I.N. Maksimchuk, A.I. Kondrashev, I.I. Shulyak. Influence of the electron structure of nanoclus-

ISSN 2071-0194. Ukr. J. Phys. 2017. Vol. 62, No. 11 
ters on the quantum yield of photoemission of magnesium alloys. Usp. Fiz. Metall. 5, 313 (2004) (in Russian).

28. V.V. Nemoskalenko, V.G. Aleshin. Theoretical Foundations of X-Ray Emission Spectroscopy (Naukova Dumka, 1974 ) (in Russian).

29. V.G. Tkachenko, Ya.V. Zaulichnyi, A.I. Kondrashev A.N. Malka, A.A. Abramov. Research of electron structure of magnesium and aluminum alloys by X-ray emission spectroscopy. Visn. Ukr. Material. Tovar. No. 1(5), 72 (2012) (in Russian).

Received 31.01.16.

Translated from Ukrainian by O.I. Voitenko

\section{А.А. Абрамов, В.Г. Ткаченко \\ ОСОБЛИВОСТІ ФОРМУВАННЯ КЛАСТЕРНИХ СПОЛУК У МЕТАЛЕВИХ ТВЕРДИХ РОЗЧИНАХ}

Р е $з$ ю е

Дана інтерпретація фізичних причин виникнення хімічних (енергетичних) зсувів оже-електронних ліній відповідних спектрів у системах Al-Li,Ba (1,4 eB) та $\mathrm{Mg}-\mathrm{Ba}(2 \mathrm{eB})$, що містять кластероутворюючі легуючі елементи, такі як Ва. Спостережувані за цими даними піки зв'язуються з формуванням кластерних сполук $\mathrm{Al}_{18} \mathrm{Ba}_{9}$ i $\mathrm{Mg}_{16} \mathrm{Ba}_{2}$ з власною електронною структурою. 